\title{
Open Pits Automobile Transport Impact on the Environment and Labor Safety
}

\author{
Portola Vyacheslav \\ T.F. Gorbachev Kuzbass State \\ Technical University \\ Kemerovo, Russian Federation \\ portola2@yandex.ru
}

\author{
Bobrovnikova Alyona \\ T.F. Gorbachev Kuzbass State \\ Technical University \\ Kemerovo, Russian Federation \\ baa.htnv@kuzstu.ru
}

\author{
Murko Elena \\ T.F. Gorbachev Kuzbass State \\ Technical University \\ Kemerovo, Russian Federation \\ zhev.httte@kuzstu.ru
}

\begin{abstract}
The automobile transport as one of significant sources of the increased danger to environment and employees of coal mines is considered in this article. The data of volumes of emissions from the automobile transport of the coal industry in the form of gaseous and solid pollutants into the atmosphere is provided in article. The analysis of influences of various factors which pollute atmosphere by coal dust is carried out in the paper. The reasons of self-ignition of coal in mines and cuts as the source of release of gaseous substances, which pollute the atmosphere, extending to considerable distances and make negative impact on adjacent territories and nearby settlements, are given.
\end{abstract}

Keywords-labor safety, coal, automobile transport, negative impact, dust formation, spoil heaps spontaneous combustion

\section{INTRODUCTION}

Surface coal extraction leads to the movement of a huge quantity of rocks, changes in the groundwater level and the redistribution of water flows. Bearing of coal seams is accompanied by bleeding from minerals and gaze reservoirs, formed during the metamorphism of coal and its oxidation by air oxygen. The operation of the coal mine is accompanied by the contamination of the atmosphere by particles of dust from coal and gaze reservoirs, as well as by evolved gazes. At the same time, water and a fertile soil layer are polluted. The coefficient of natural resources usage is in the range from 0.02 to 0.1 . The greater part of the extracted resources is returned to the surrounding environment with deteriorated composition and properties [1-8]. At coal mines, there is also an increased level of risk of hazardous and harmful factors to people, which leads to injuries and diseases.

\section{MATERIALS \& METHODS}

Motor transport, transporting rock and coal constitutes danger to the environment and coal mines workers. The accident analysis showed that up to $30 \%$ of injuries in open cast mining operations are caused by transport. The main cases of transport traumatism are fallings of dump trucks into dumps (during unloading), drift of vehicles (when driving), when towing vehicles, collision of dump trucks. $27 \%$ of fatal cases are the transport employees of coal mines. The main causes of injuries are violations of safety rules and technological processes, equipment failure. When servicing and repairing machines, the main causes of injuries are deviations from technological rules of work performance, unreliable organization of work, insufficient personnel knowledge to perform the work safely. The level of occupational diseases of workers in coal mines is still high. The most common disease of coal mine employees is damage of the respiratory tract due to the effects of dust and toxic gases. Vibration syndrome is also common.

Motor transport of coal mines also causes significant damage to the environment. Negative impact on nature can be direct and indirect. Direct damage is due to exhaust gases, generated by the fuel combustion of engines. Thus, the power of the engine installed in a dump truck BelAZ 75131 is $1194 \mathrm{~kW}$, its working volume is 50 liters and fuel consumption is 195 liters per 100 kilometers. Significant direct impact on the environment is caused by dust release, when driving, loading and unloading of coal and rock. As a rule, the area of negative impact of coal mines extends to areas that are much larger than the area of mining enterprises, taking areas where people live.

An example of coal mines effect on dust formation is the open pit "Kedrovsky". Removal of overburden to external dumps is carried out by rail and road transport. Transportation of overburden by motor transport (BelAZ-548, BelAZ-75191, BelAZ-75214, BelAZ-75128, etc.) is carried out to external bulldozer dumps. The results of measuring of dust content in the driver's cabin at the loading site under different climatic conditions are given in table. 1 .

Analysis of the data shows that the amount of dust in the cabin in the summer period is 3 times higher than in the winter. The lowest dust content is observed in the autumnspring period (20 times less than in the summer). Analyzing the obtained results, it can be concluded that the humidity and temperature of rocks exert the greatest influence on the process of dust formation. Distribution of precipitation during the year at "Kedrovsky" open pit is given in table 2.

TABLE I. THE RESULTS OF MEASURING OF DUST CONTENT IN THE DRIVER'S CABIN AT THE LOADING SITE UNDER DIFFERENT CLIMATIC CONDITIONS.

\begin{tabular}{|c|c|c|}
\hline Air temperature, ${ }^{\circ} \mathrm{C}$ & Relative humidity, \% & $\begin{array}{l}\text { Dust content in a } \\
\text { cabin, } \mathrm{mg} / \mathrm{m}^{3}\end{array}$ \\
\hline-4.0 & 77 & 14.2 \\
\hline-2.6 & 68 & 16.6 \\
\hline+6.8 & 76 & 2.5 \\
\hline+22.8 & 55 & 40.3 \\
\hline+29.8 & 42 & 50.8 \\
\hline+30.4 & 73 & 57.6 \\
\hline
\end{tabular}


TABLE II. DISTRIBUTION OF PRECIPITATION DURING THE YEAR AT "KEDROVSKY" OPEN PIT.

\begin{tabular}{|l|c|c|c|}
\hline Season & $\begin{array}{c}\text { Average number of } \\
\text { days with } \\
\text { precipitation }\end{array}$ & $\begin{array}{c}\text { Precipitation, } \\
\text { mm }\end{array}$ & $\begin{array}{c}\text { Percentage of } \\
\text { annual } \\
\text { precipitation, \% }\end{array}$ \\
\hline Winter & 30 & 26.7 & 7.9 \\
\hline Spring & 34 & 82.9 & 23.6 \\
\hline Summer & 30 & 68.9 & 21.1 \\
\hline Autumn & 40 & 158 & 47.4 \\
\hline
\end{tabular}

\section{RESULTS \& DISCUSSION.}

According to the given data, it can be seen that the greatest amount of precipitation is in spring and autumn. At the same time, due to low temperature and high relative humidity of air, the evaporation of liquid from the rocks is reduced; it allows to maintain high humidity for a long time. As a result, minimal dust formation is observed during this period.

In winter, lasting for 5-6 months, the surface of the open pits and rock dumps is covered by snow, which reduces the emission of dust in comparison with the summer period. In summer, solar radiation and high air temperature lead to rapid drying of rocks and increased dust formation.

The dust concentration in air and the range of its distribution also depend on the wind speed. In the open pit "Kedrovsky" wind of the southern direction (39\%) and south-west direction $(26 \%)$ prevail during the year, while no wind condition is $30 \%$. The average annual wind speed is 2.8 $\mathrm{m} / \mathrm{s}$.

Taking into account that the humidity of rock dumps is the only factor under control and it influences dust formation, it is advisable to calculate the amount of formed dust on the rock dumps of the open pit "Kedrovsky" with different rocks moisture level. The release of solid particles into the atmosphere during the formation of rock dumps can be determined by the formula (1):

$$
\mathrm{M}_{\mathrm{f}}=\mathrm{K}_{1} \mathrm{~K}_{0} \mathrm{PC}(1-\mathrm{p}) 10^{-6}
$$

where $\mathrm{K}_{1}$ - index, taking into account wind speed (1.2); $\mathrm{K}_{0}$ - index, taking into account the moisture content of the material $(0.1$ at the humidity of overburden from 11.9 to $13.9 \%) ; \mathrm{C}-$ specific release of solid particles from one cubic meter of rock; $\mathrm{P}$ - the amount of rock given to the dump; $\mathrm{p}-$ the efficiency of the dust suppression methods.

The volume of the dump, formed by the railway overburden is 7307 thousand m3/year, and by motor transport is 27186 thousand $\mathrm{m} 3 /$ year. Calculated data of the effect of humidity on rocks on the amount of dust re-leased from the rock dumps at the open pit "Kedrovsky" are shown in Fig. 1.

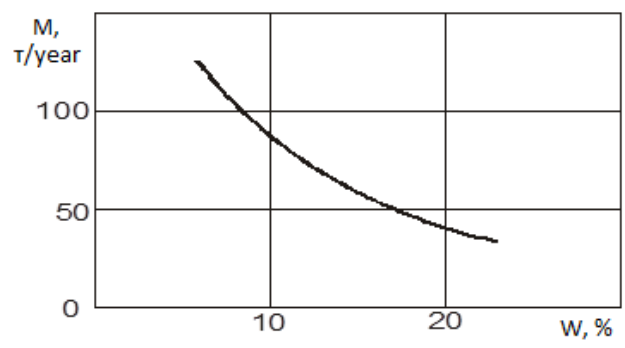

Fig. 1. Dust formation from rock dumps of the open pit, depending on the moisture content of the rocks
From the given data it can be seen that the humidification of rock dumps surface can reduce the mass of dust released into the atmosphere in several times. The obtained results make it possible to calculate the amount of water required and the periodicity of humidification, depending on atmospheric meteorological conditions to maintain the dust content of the air at the required level.

Indirect damage to the environment caused by the use of motor transport at coal mines can result from heating of transported coal and carbonaceous rocks. Thus, the dump trucks used at the open pits have a car body heating system with exhaust gases. Such heating prevents the transported rocks freezing in the winter. However, in the summer period, the car body heating system heats rocks. The measurements showed that the surface of the car body can be heated to a temperature of $100{ }^{\circ} \mathrm{C}$ or more. Coal can be oxidized by air oxygen at natural temperatures. The amount of heat, released during the interaction of oxygen with carbon-bearing rocks, depends on the temperature and can be determined by the following formula:

$$
\mathrm{Q}=\mathrm{q} \rho \mathrm{Cke} \mathrm{e}^{-\mathrm{E} / \mathrm{RT}}
$$

where $\mathrm{q}-$ the thermal effect of the oxidation reaction; $\rho-$ the density of the cluster; $\mathrm{C}$ - the oxygen concentration; $\mathrm{k}-$ the oxidation rate constant; $\mathrm{E}$ - the activation energy; $\mathrm{R}$ - the gas constant; $\mathrm{T}$ - the temperature.

It is clear from the above equation that the increase in the temperature of the accumulation of carbonaceous rocks leads to the exponential increase in the amount of heat released. The ratio of the amount of heat released as a result of interaction with oxygen of the coal-bearing rock at different temperatures $\mathrm{T} 0$ and $\mathrm{T} 1$ can be described by the equation:

$$
\mathrm{Q}_{1} / \mathrm{Q}_{0}=\mathrm{e}^{\mathrm{E}\left(\mathrm{T}_{1}-\mathrm{T}_{0}\right) \mathrm{RT}_{1} \mathrm{~T}_{0}}
$$

where $\mathrm{Q}_{0}$ - the amount of heat released at the natural temperature $\mathrm{T}_{0} ; \mathrm{Q}_{1}$ - the amount of heat released at the elevated temperature $\mathrm{T}_{1}$.

Calculation by formula (3) shows that when the carbonaceous rock is heated with an activation energy of 42 $\mathrm{kJ} / \mathrm{mol}$ from 20 to $50{ }^{\circ} \mathrm{C}$, the amount of released heat increases by 5 times, and in the case of warming up to $70^{\circ} \mathrm{C}$ the amount of heat generated increases by 12.4 times. Thus, it can be seen from the given calculations that the initial heat pulse is the most important factor for the development of the process of spontaneous combustion in low-activity carbonaceous rocks at natural temperature.

In the case of spontaneous combustion of coal and carbonaceous rocks, toxic gases such as carbon monoxide, hydrogen sulphide and sulfurous anhydride are formed, capable to spread over long distances, often reach working and residential areas, exceeding the maximum permissible concentrations. In addition, at burning rock dumps explosions are possible due to intensive evaporation in case of water entering the incandescent cavities.

The fulfilled researches showed that the surface of the rock dump is heated unevenly. High-temperature zones are mainly formed in the places of cracks occurrence, disturbances of the compacted surface (loosened areas), in uplands and on the slopes of dumps. The temperature of the surface in such areas was $130-200{ }^{\circ} \mathrm{C}$. In places on the slopes of the dumps, where there is intensive air supply, there was open fire; the temperature of the incandescent rocks reaches 
$500-600{ }^{\circ} \mathrm{C}$. On the flat surface of the dump the rock temperature is $30-60{ }^{\circ} \mathrm{C}$.

The concentration of carbon monoxide near the surface of the dump fluctuated over a wide range, depending on the temperature and compactness of rocks. Over the friable heated surface, the concentration of carbon monoxide reached $0.05 \%$. In some places methane was detected (up to $0.5 \%$ ) and hydrogen was reduced to $0.1 \%$. The conducted measurements showed that over the heated surface of the dump there is an increased release of radon $[9,10]$. Thus, the background fluxes of radon from the surface of the dump were $30-60 \mathrm{mBq} /\left(\mathrm{m}^{2} \cdot \mathrm{s}\right)$. In the areas of self-heating the radon flux reached values of $300-450 \mathrm{mBq} /\left(\mathrm{m}^{2}\right.$. s). The intensity of radon emission depends not only on the temperature of the rocks, their permeability, but also on the air temperature. When the air cooled, radon fluxes increased at a constant temperature of the self-heating areas.

Thus, the conducted studies have shown that the concentration of carbon monoxide and radon fluxes at some areas of the dump surface can significantly exceed the permissible sanitary standards for work areas. There is an uneven heating of the surface of the rock dump and the release of hazardous gases. An interesting fact is the increased concentration of hydrogen in some areas of the dump.

\section{CONCLUSIONS}

1. Motor transport of coal mines represents the increased risk to people, causing injuries (up to $30 \%$ of all cases) and occupational diseases. Motor transport of the open pits negatively affects the environment due to the release of dust and toxic gases.

2. The source of dust at open pits is the transportation, loading and unloading of coal and rock. The dust content of the air in the open pit depends on the time of the year, the air temperature and the amount of atmospheric precipitation. The highest dust content was recorded in the summer.
3. Motor transport can be the cause of spontaneous combustion of coal and rock dumps due to the heating of the transported rock mass with exhaust gases in the truck body. 4. Emerging on the spoil heaps spontaneous combustion leads to uneven heating of the rock mass, increased release of carbon monoxide, radon and other gases.

\section{REFERENCES}

[1] S. Goswami, "Environmental Impact Assessment of Coal Mining: Indian Scenario,” European Researcher, vol. 83(9-2), pp. 1651-1661, 2014.

[2] P.T. Xuan, N.Van Pho, O.L. Gas'kova, and S.B. Bortnikova, "Geochemistry of surface waters in the vicinity of open pit mines at the Cay Cham deposit, Thai Nguyen province, northern Vietnam," Geochemistry Insternational, vol. 51(11), pp. 931-938, 2013.

[3] G. Žibret, D. Van Tonder, and L. Žibret, "Metal content in street dust as a reflection of atmospheric dust emissions from coal power plants, metal smelters, and traffic," Environmental Science and Pollution Research, vol. 20(7), pp. 4455-4468, 2013.

[4] A.V. Nazarkina, O.D. Arefieva, T.M. Kadyrova, L.G. Buvanova, and E.M. Savenkova, "Impact of Mine Waters of Abandoned Coal Mine «Avangard» on the Environment," Advanced Materials Research, pp. 807-809:158-161, 2013.

[5] V.A. Portola, "Assessment of the effect of some factors on spontaneous coal combustion," Journal of Mining Science, vol. 32(3), pp. 212-218, 1996.

[6] S. Goswami, "Impact of coal mining on environment," European Researcher, Series A, vol. 92(3), pp. 185-196, 2015.

[7] V. Saini, R.P. Gupta, and M.K. Arora, "Environmental impact studies in coalfields in india: a case study from jharia coal-field," Renewable and Sustainable Energy Reviews, vol. 53, pp. 1222-1239, 2016.

[8] T.G. Cherkasova, "Rare earth elements in kuznetsk coals: ability to excavate and new functional materials," Chinese Coal in the XXI Century: Mining 2014. Taishan Academic Forum - Project on Vine Disaster Prevention and Control. Mining, Green and Safetypp., pp. 418-420, 2014.

[9] V.A. Portola, E.S. Torosyan, and V.K. Antufeyev, "Radon Emission from Coal Mines of Kuzbass Region," IOP Conference Series: Materials Science and Engineering, p. 127, 2016.

[10] M.Y. Shpirt and S.A. Punanova, "Estimated radioactivity of solid fossil fuels," Solid Fuel Chemistry, vol. 48(1), pp. 1-10, 2014. 